\title{
Los conceptos de calidad, idoneidad y seguridad en el nuevo estatuto del consumidor ${ }^{1}$
}

\author{
Alejandro Giraldo López²
}

\section{RESUMEN}

En esta ponencia elaborada para el foro "Nuevo Estatuto del Consumidor", organizado por la Universidad Externado de Colombia, el autor expone los conceptos de calidad, idoneidad y seguridad a la luz del nuevo Estatuto del Consumidor, comparando paralelamente los principales cambios con el antiguo Estatuto de Protección al Consumidor. Esta breve pero ilustrativa ponencia culmina con un análisis detallado del régimen de responsabilidad en materia del derecho del consumidor.

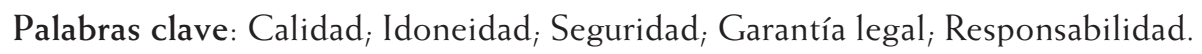

1 Ponencia elaborada para el foro "Nuevo Estatuto del Consumidor", organizado por la Universidad Externado de Colombia, el 14 de septiembre de 2011. Primero que todo, quiero agradecer a la Universidad Externado de Colombia, y en especial al equipo que conforma el Departamento de Derecho Económico, no solo por organizar la presente jornada, la primera que se realiza después de su aprobación definitiva en el Congreso de la Republica, sino porque por más de 5 años acogió en su seno al grupo de personas que con tanto empeño trabajaron en la redacción del texto que hoy se presenta como el nuevo Estatuto del Consumidor. Para citar el artículo: Giraldo López, A. (2014). "Los conceptos de calidad, idoneidad y seguridad en el nuevo estatuto del consumidor", en Revista Con-texto, n. ${ }^{\circ} 42$, pp. 55-67. DOI: http://dx.doi.org/10.18601/ $01236458 . \mathrm{n} 42.05$

2 Abogado del Colegio Mayor de Nuestra Señora del Rosario (1994), magíster en sociología jurídica del International Institute for the Sociology of Law de España (1998), terminó estudios de doctorado en sociología en la Universidad de Salamanca (1999) y recientemente se graduó de magíster en Derecho económico de la Universidad Javeriana (2011). Se ha desempeñado como Asesor del Superintendente de Industria y Comercio (2000-2003) y como Vicepresidente Jurídico de Fenalco (2004-2010). Entre octubre de 2010 y febrero de 2012, se desempeñó como Superintendente Delegado para la Protección al Consumidor, y en la actualidad es el Superintendente Delegado para el Control y Verificación de Reglamentos Técnicos y Metrología Legal de la Superintendencia de Industria y Comercio. Es profesor de posgrado de las universidades Rosario, Javeriana, Andes y Externado en Derecho del consumo y de la competencia, coautor de los libros Comentarios al Nuevo Estatuto del Consumidor y Metodología y Técnica de la Investigación Sociojurídica, y escritor de artículos para revistas especializadas en derecho económico y derecho de los mercados. Correo-e: agiraldo@sic.gov.co. 


\section{THE CONCEPTS OF QUALITY, SUITABILITY AND SECURITY IN THE NEW CONSUMER STATUE}

\section{ABSTRACT}

In this paper, that was elaborated for the forum "Nuevo Estatuto del Consumidor" which was organized by the Universidad Externado de Colombia, the author explores the concepts of quality, suitability and security in the new Consumer Statute and, also, briefly explains the most significant changes with the past Consumer Protection Statute. This short but illustrative paper concludes with a detailed analysis of the strict liability that applies in consumer law.

Keywords: Quality; Suitability; Security; Legal Warranty; Liability.

El tema que abordaré está relacionado con los conceptos de calidad, idoneidad y seguridad, y la forma de hacer efectiva la garantía por parte de los consumidores en el nuevo Estatuto del Consumidor, con una breve comparación con el antiguo Estatuto de Protección al Consumidor.

El primer cambio relevante se dio en la definición de "calidad". El antiguo Estatuto la definía como "[e]l conjunto total de las propiedades, ingredientes o componentes que lo constituyen, determinan distinguen o individualizan. La calidad incluye la determinación de su nivel o índice de contaminación y de los efectos conocidos que ese nivel de contaminación puede producir" ${ }^{\prime \prime}$. Esta definición relacionaba el concepto de calidad con las características propias de cada bien que lo individualizaban frente a los demás, de tal forma que era inapropiado hablar de un bien de buena o mala calidad, y simplemente se podía hacer referencia a un bien que tenía o no tenía las propiedades, ingredientes o componentes que lo individualizaban. Para ejemplificar este concepto, imaginemos la persona que compra un vehículo $\mathrm{X}$ y, al momento de reclamarlo, le entregan un vehículo Y. Independientemente de si el vehículo Y tiene mejor desempeño, velocidad o fuerza que el vehículo $X$, habría un problema de calidad, en el sentido de que el primero tendría características diferente a las del vehículo Y.

En el nuevo Estatuto, se define calidad como la "[c]ondición en que un producto cumple con las características inherentes y las atribuidas por la información que se suministre sobre él"4. En esta definición, más acorde con la que trae la norma internacional de calidad ISO $9000^{5}$, las características inberentes corresponden a las características propias,

3 Dec. 3466/82, art. 1 lit. f)

4 E. del C., Art. 5 num. 1).

5 Calidad: grado en el que un conjunto de características (3.5.1) cumple con los requisitos (3.1.2) NOTA 1 El término "calidad" puede utilizarse acompañado de adjetivos tales como pobre, buena o excelente. 
obvias de cualquier producto de similares condiciones, que espera el consumidor que cumpla sin necesidad de que se las hagan expresas. Por otra parte, las características atribuidas por la información que se suministre de él, son las adicionales, no obvias, dadas a conocer por el productor o proveedor en su proceso de comercialización.

En cuanto a la idoneidad de los productos, si bien existe una diferencia en la redacción de la nueva definición frente a la antigua, el cambio sustancial no es mayor. El antiguo Estatuto de Protección al Consumidor la definía como "[s]u aptitud para satisfacer la necesidad o necesidades para las cuales ha sido producido, así como las condiciones bajo las cuales se debe utilizar en orden a la norma y adecuada satisfacción de la necesidad o necesidades para las cuales está destinado" ${ }^{\prime 6}$. El nuevo Estatuto del Consumidor, por su parte, la define como la "[a]ptitud del producto para satisfacer la necesidad o necesidades para las cuales ha sido producido o comercializado"7. La finalidad es la misma, que un bien sirva para lo que está hecho: un radio debe recibir señal de emisoras y oírse adecuadamente, un camión debe soportar cargas para transportar o una lavadora debe dejar la ropa limpia y sin deterioros. Sin embargo, es muy importante tener en cuenta los requerimientos del consumidor al momento de comprar, cuando este los ha hecho expresos, es decir, si alguien requiere al vendedor para que le venda un computador que le sirva para correr complejos programas estadísticos y de gráficos, y este le vende un computador que en condiciones normales es bueno, pero no le sirve al consumidor para cumplir con la finalidad para lo cual lo adquirió, habrá un problema de idoneidad del bien, por el cual tendrá que responder el vendedor.

En cuanto al tercer concepto que nos ocupa, el de seguridad, es novedoso en nuestra legislación, definido en el nuevo Estatuto como la "[c]ondición del producto conforme con la cual en situaciones normales de utilización, teniendo en cuenta la duración, la información suministrada en los términos de la presente ley y si procede, la puesta en servicio, instalación y mantenimiento, no presenta riesgos irrazonables para la salud o integridad de los consumidores. En caso de que el producto no cumpla con requisitos de seguridad establecidos en reglamentos técnicos o medidas sanitarias, se presumirá inseguro $^{\prime \prime}$. Este concepto hace referencia a que ningún producto en el mercado, utilizado de forma normal y razonable, puede causar un daño o perjuicio a los consumidores. La seguridad no está necesariamente relacionada con la calidad o idoneidad del bien: un bien puede ser idóneo, pero inseguro; o ser no idóneo pero ser seguro. Más claro con un ejemplo: un celular puede funcionar muy bien recibiendo y emitiendo llamadas; por tanto, es idóneo. Pero si este mismo celular emite radiaciones por encima del nivel establecido por los estándares internacionales, será inseguro. Caso contrario es el del televisor que no prende o que se apaga repentinamente: será seguro porque no causa ningún daño al consumidor más allá de la molestia de tener que solicitar su reparación.

NOTA 2 "Inherente", en contraposición a "asignado", significa que existe en algo, especialmente como una característica permanente.

6 Dec. $3466 / 82$ art. 1 lit. e.

$7 \quad$ E. del C., Art. 5 num. 6).

$8 \quad$ E. del C., Art. $5^{\circ}$ num. 14). 
Pero para determinar si un bien es seguro o inseguro, es necesario tener en cuenta, como lo dice la norma, "la duración, la información suministrada en los términos de la presente ley y, si procede, la puesta en servicio, instalación y mantenimiento"9. Así, por ejemplo, si un bien perecedero que fue puesto en el mercado en condiciones seguras causa un daño al consumidor porque este, por descuido, lo consumió con posterioridad a su fecha de vencimiento o no le mantuvo su cadena de refrigeración y por eso se descompuso, obviamente no será responsable ni el productor ni el proveedor de dicho bien. También es importante tener presente que no por el hecho de que salgan al mercado productos más seguros, quiere decir que los anteriores productos sean inseguros; es decir, si hoy existen en el mercado algunos carros con sistemas de airbag para evitar lesiones en los accidentes, los que no tienen dicho dispositivo no son, por ese simple hecho, vehículos inseguros, mientras una norma de carácter imperativo no los obligue a tenerlos.

Relacionado con el concepto de seguridad, el nuevo Estatuto también definió el concepto de "producto defectuoso" como "aquel bien mueble o inmueble que en razón de un error en el diseño, fabricación, construcción, embalaje o información, no ofrezca la razonable seguridad a la que toda persona tiene derecho ${ }^{10}{ }^{10}$. Téngase en cuenta que dicha definición es solo para productos defectuosos que causan un daño. Los productos con defectos que no causan un perjuicio pero que deben ser reparados o cambiados, no requieren ser inseguros para que sea procedente la garantía.

Ahora bien, entendidos los conceptos de calidad, idoneidad y seguridad, vamos a revisar cuáles son las exigencias legales que debe cumplir todo productor antes de colocar un producto en el mercado. El artículo 6 del nuevo Estatuto del Consumidor establece que, conforme a lo anterior, todo producto puesto en el mercado debe ser idóneo -según sus características y calidades- y seguro; aquí no existen graduaciones: o cumple o no cumple. La calidad, por el contrario, puede estar determinada libremente por el productor, si no existe disposición de carácter obligatorio que fije unas condiciones mínimas de calidad, como cuando se está sujeto al cumplimiento de un reglamento técnico o a una medida sanitaria o fitosanitaria, o sus condiciones están regidas por un registro sanitario; en estos casos, la calidad de un producto nunca podrá ser inferior a lo establecido en la norma. Pero, lo más importante, la obligación principal del productor es informar a los consumidores la calidad que tienen los productos que coloca en el mercado. En caso de que no informe, sin perjuicio de que las sanciones a que haya lugar por ineficiencia en la información, el parámetro de calidad será el de las condiciones ordinarias y habituales del mercado para productos similares. Lo anterior quiere decir que si alguien quiere producir zapatos con suela de cartón -como dice la canción-, que se deshacen con el primer aguacero, lo podrá hacer siempre que no haya una norma imperativa que imponga requisitos de calidad a los zapatos, y en tanto informe adecuadamente a los consumidores acerca del material del que están hechos y les advierta del riesgo de quedar descalzos en el primer charco que se pise. 
El incumplimiento de las condiciones de calidad exigibles por parte del consumidor o de la idoneidad del producto, generan dos tipos de responsabilidad para los productores y expendedores: la primera, civil, es decir, la de cumplir con la garantía frente al consumidor, la cual es solidaria, el consumidor puede reclamar indistintamente al productor o al proveedor, quienes deberán cumplir con las obligaciones que impone la ley, sin perjuicio de que quien respondió luego pueda repetir contra el responsable del defecto del bien. La otra es administrativa, frente a las autoridades de vigilancia y control, que es de carácter individual; es decir, la autoridad competente solo podrá imponer sanciones y medidas correctivas a quien sea el directo responsable por la existencia del defecto en el bien.

En cuanto al incumplimiento de las condiciones de seguridad del producto que causan un daño o perjuicio a los consumidores o a bienes diferentes al producto defectuoso, se genera entonces la llamada "responsabilidad por daños causados por producto defectuoso" de que trata el Título IV del Estatuto, del cual no nos ocuparemos en la presente disertación.

Entonces, cuando un producto presenta un defecto, surge el derecho para el consumidor de reclamar por la garantía. La garantía está definida como la "[o]bligación temporal, solidaria, a cargo del productor y el proveedor, de responder por el buen estado del producto y la conformidad del mismo con las condiciones de idoneidad, calidad y seguridad legalmente exigibles o las ofrecidas. La garantía legal no tendrá contraprestación adicional al precio del producto" ${ }^{11}$. Por su parte, la garantía legal, dice el artículo 7, "[e]s la obligación, en los términos de esta ley, a cargo de todo productor y/o proveedor de responder por la calidad, idoneidad, seguridad y el buen estado y funcionamiento de los productos". Los productos entregados en "promoción", como cuando se venden con descuentos o rebajas, también están cubiertos con la misma garantía de cualquier otro producto adquirido en condiciones normales de mercado.

El término mínimo por el cual debe garantizase el buen estado y funcionamiento del bien, se establece de tres formas. En primera medida, la Superintendencia de Industria y Comercio puede fijar el término de garantía mínimo legal cuando lo considere necesario $^{12}$. A falta de disposición de obligatorio cumplimiento, será entonces el anunciado por el productor y/o proveedor ${ }^{13}$; y en caso de que este guarde silencio, la garantía se presumirá de la siguiente forma: para bienes nuevos duraderos, será de un (1) año; para bienes perecederos, será la fecha de vencimiento o expiración, para productos usados y para servicios de reparación, será de tres (3) meses. En estos dos últimos casos -usados y servicios de reparación-, se podrá vender o prestar el servicio sin garantía, siempre y cuando se le informe adecuadamente al consumidor y este acepte por escrito dicha condición. En cuanto a los bienes inmuebles, la ley estableció una garantía mínima legal de 10 años para la estabilidad de la obra, y de un (1) año para los acabados.

Ahora bien, la nueva ley resolvió dos discusiones que se tuvieron por muchos años, relacionadas con las consecuencias de que un producto entrara en garantía: primero, 
con el tiempo en que el consumidor no podía disfrutar del bien mientras este estaba en reparación; y segundo, con el término de garantía cuando se cambiaba el bien completo o alguna de sus piezas. El artículo 9 dispuso que "[e]1 término de la garantía se suspenderá mientras el consumidor esté privado del uso del producto con ocasión de la efectividad de la garantía". Y, a renglón seguido, aclaró que "[s]i se produce el cambio total del producto por otro, el término de garantía empezará a correr nuevamente en su totalidad desde el momento de reposición. Si se cambia una o varias piezas o partes del bien, estas tendrán garantía propia". De esta forma, se zanja definitivamente la discusión de si la garantía es un tema netamente contractual o es una característica jurídica inherente a los productos que se comercializan en el territorio nacional, inclinándose por esta última interpretación.

Un elemento fundamental del derecho del consumidor quedó establecido en el artículo $10{ }^{\circ}$, y tiene que ver con la inversión de la carga de la prueba a favor del consumidor. Dice así dicho artículo: "Para establecer la responsabilidad por incumplimiento a las condiciones de idoneidad y calidad, bastará con demostrar el defecto del producto, sin perjuicio de las causales de exoneración de responsabilidad establecidas en el artículo 16 de la presente ley". Conforme a este artículo, el consumidor solo está obligado a probar que el bien tiene un defecto, sin necesidad de demostrar las causas que lo generar; esta carga probatoria la asume e productor o expendedor, quien deberá demostrar que el defecto se generó por una de las causales de exoneración de responsabilidad establecidas taxativamente en el artículo 16 de dicha ley, a las cuales nos referiremos más adelante. Esta es una inversión de la carga de la prueba, porque en las reglas tradicionales de responsabilidad, como en el saneamiento por vicios ocultos, el demandante no solo debe demostrar el defecto del bien, sino, además, que este existía con anterioridad a su venta. Vale la pena agregar que esta característica del derecho del consumidor ha sido analizada y avalada tanto por la Corte Constitucional ${ }^{14}$ como por la Corte Suprema de Justicia ${ }^{15}$ en sendas ocasiones.

"El empresario profesional, en este caso, es el sujeto que debe enfrentar y soportar un juicio de imputación de responsabilidad, no por tratarse propiamente de un riesgo de empresa, sino fundamentalmente por el hecho de haber puesto en circulación un producto defectuoso. El defecto cuya prueba compete al perjudicado, no es el error de diseño o intrínseco del producto, cuyo conocimiento difícilmente puede dominar o poseer el consumidor; lo es la inseguridad que se manifiesta con ocasión del uso al cual está destinado. Probado el defecto resulta razonable suponer que la responsabilidad corresponde al empresario que controla la esfera de la producción, la organiza, dirige y efectúa el control de los productos que hace ingresar al mercado y, por ende, para liberarse debe éste a su turno demostrar el hecho que interrumpe el nexo causal.

"(...)

"La posición del consumidor no le permite conocer en detalle el proceso de producción, más aún si éste se desarrolla en condiciones técnicas que solamente son del dominio del empresario industrial. La ley, por lo tanto, desconoce las circunstancias de inferioridad del consumidor cuando, en estos supuestos, exige a la persona perjudicada con un producto defectuoso, puesto en circulación por un empresario profesional, cargas adicionales a la prueba del daño, del defecto y del nexo causal entre este último y el primero, puesto que acreditado este extremo, corresponderá al empresario demostrar los hechos y 
Otro elemento básico del derecho del consumo está dado por el tipo de responsabilidad que se deriva de las causales de exoneración de responsabilidad establecidas en la ley ${ }^{16}$. En ellas se prevén como tal la fuerza mayor o el caso fortuito, el hecho de un tercero que causa el defecto, el uso indebido del bien por parte del consumidor y la falta de seguimiento de las instrucciones de instalación, uso o mantenimiento. Todas estas causales se pueden resumir en una sola: el hecho extraño, ajeno totalmente a la órbita de control del productor o proveedor. Fíjense que de nada sirve alegar o demostrar que se es muy diligente y prudente en la elaboración de sus productos, que cuenta con certificados de calidad o alto nivel de capacitación de sus empleados, y que por ello se puede exonerar de responsabilidad; eso no es posible. La responsabilidad en materia de protección al consumidor es una responsabilidad objetiva, y punto. Quien coloca un producto en el mercado y sale defectuoso, debe responder y otorgar garantía, y si además causa daño, debe indemnizar los perjuicios que cause.

Sin embargo, no basta con solo demostrar el hecho eximente de responsabilidad. También es necesario demostrar el vínculo causal entre este y el defecto del bien. Por ejemplo, cuando en los televisores, equipos de sonido y otros electrodomésticos encontramos cintas que sellan el producto y advierten: "Si se rompe este sello, se pierde la garantía", dicha advertencia no tiene ninguna validez jurídica. El hecho de que se encuentre el sello roto, a lo sumo lo único que indica es que hubo una intervención, pero eso no

circunstancias que lo eximan de responsabilidad y que, en su caso, conforme a las reglas legales y a las pautas jurisprudenciales, le permitan excluir la imputabilidad causal del hecho dañoso sufrido por aquélla. "Ninguna utilidad práctica, en verdad, tendría el derecho del consumidor, elevado a norma constitucional, si las leyes que lo desarrollan no se notifican de las situaciones de inferioridad del consumidor y restablecen el equilibrio con los actores de la vida económica, principalmente permitiéndole franquear las instituciones procesales de resarcimiento de perjuicios sin que se le impongan condiciones excesivamente gravosas que escapan a su control y que se erigen en obstáculos mayúsculos para deducir la responsabilidad a los productores que quebrantan las condiciones de seguridad a las que tiene derecho". Sentencia de la Sala Civil Corte Suprema de Justicia del 30 de abril de 2009, M.P. Pedro Octavio MUNAR CADENA:

"Para comprobar el defecto de seguridad que afecta al producto, no debe la víctima incursionar en el examen del proceso de fabricación para demostrar que el defecto se debe a un diseño desacertado o a una indebida fabricación, sino que se debe limitar a probar que éste no ofrecía la seguridad a la que una persona tiene legítimamente derecho.

"Es claro que los jueces pueden deducir, atendiendo las circunstancias del caso (el embalaje del objeto, los usos sociales y mercantiles, o la imposibilidad de haber sido manipulado por terceros, etc., ) que fue el fabricante quien introdujo el producto defectuoso en el mercado y le corresponderá a éste demostrar lo contrario.

"(...)

"En síntesis, si bien puede decirse que corresponde a la víctima desarrollar una ardua tarea en materia probatoria, lo cierto es que la carga que le incumbe se atenúa en cuanto le es dado al juzgador presumir a) que el producto ha sido puesto en circulación por el fabricante o productor $;$ b) que el defecto existía en el momento en el que se introdujo en el mercado, y c) y que fue el fabricante quien lo elaboró para venderlo".

Artículo $16^{\circ}$. 


\section{demuestra de forma alguna que, aun en el evento de haber existido dicha intervención, haya sido la que generó el defecto del bien ${ }^{17}$.}

17 La Corte Constitucional, en sentencia C-973 de 2002, M.P.: ÁlVARO TAFuR GALVIS, se pronunció al respecto y sostuvo que:

"Ahora bien, frente a las causales de exoneración a que se refiere la norma cabe diferenciar aquellas en las que el nexo causal de la responsabilidad se rompe en circunstancias que son totalmente ajenas al productor, de aquellas en las que al menos de manera indirecta éste tiene algún tipo de vínculo con el daño causado.

"Así es pertinente diferenciar los casos en que se está frente a la fuerza mayor, el caso fortuito no sobrevenido por culpa del productor, el uso indebido del bien o servicio por parte del afectado, o el hecho de un tercero no ligado al productor, de los casos en que el daño sobrevenga como resultado de un caso fortuito generado por el productor, o por el hecho de un tercero ligado a él mediante relación de trabajo o contractual de cualquier clase, circunstancias en las que dicho productor o bien se encuentra en el origen del perjuicio causado o bien tiene de alguna manera la posibilidad de incidir en la determinación de la calidad del bien o servicio que llegue a resultar deficiente y que pueda causar daños a los consumidores y usuarios.

"(...)

"Al respecto la Corte constata que cuando el artículo 26 del Decreto Ley 3466 de 1982 señala que sólo son admisibles como causales de exoneración de la responsabilidad del productor la fuerza mayor, el caso fortuito no sobrevenido por su culpa, el uso indebido del bien por parte del afectado o el hecho de un tercero ligado o no al productor mediante relación de trabajo o contractual de cualquier clase, debidamente probados conforme al procedimiento indicado en el mismo decreto, reduce exclusivamente a la demostración de alguna o algunas de dichas causales su posibilidad de aportar pruebas o presentar alegaciones para defenderse con el fin de no ser sometido a las sanciones anotadas o al pago de la indemnización aludida.

"Es decir, que si bien el productor podrá en las diferentes etapas del procedimiento establecido en el artículo 28 del Decreto Ley 3466 de 1982 o en las demás instancias procesales que se establecen tanto en el Código Contencioso Administrativo para el caso de las sanciones, como en el Código de Procedimiento Civil para el caso de la indemnización de perjuicios, presentar pruebas, controvertir las que se presenten en su contra, y en general hacer uso de los recursos que dichos procedimientos establecen, el ámbito de su defensa no podrá desbordar la demostración del acaecimiento de dichas causales, con lo que efectivamente puede considerarse que se presenta una limitación a su derecho de defensa.

"Cabe precisar que bien podría aducirse que por este medio simplemente se están determinando con claridad los eventos en los cuales el nexo causal del daño se rompe, liberando a quien en principio está llamado a responder y así limitar su responsabilidad ${ }^{29}$. Sin embargo para la Corte es claro que esa circunstancia en todo caso implica una delimitación del ámbito en el que el productor puede ejercer su derecho de defensa para lograr la exoneración de su responsabilidad, y en este sentido implica una limitación de su derecho.

"Ahora bien, dicha limitación no puede considerarse como una vulneración del derecho al debido proceso del productor, por cuanto como se señaló en los apartes preliminares de esta providencia, éste como todo derecho fundamental no tiene un carácter absoluto y bien puede ser limitado por el legislador en ejercicio de su potestad de configuración de los procedimientos judiciales y administrativos, siempre y cuando exista una justificación basada en la prosecución de un fin constitucionalmente protegido y que dicha limitación no resulte desproporcionada, al punto que se desconozca el núcleo esencial de derecho al debido proceso, y en particular el derecho de defensa reconocido por la Constitución.

"En el presente caso, dicha justificación no solamente se encuentra en el mandato constitucional de asegurar el control de calidad de los bienes y servicios ofrecidos y prestados a la comunidad así como la responsabilidad de quienes en su producción y comercialización atenten contra la salud, la seguridad, y el adecuado aprovisionamiento a consumidores y usuarios, sino en el particular ámbito de protección que la Constitución establece para los consumidores (artículo 78 C.P.)".

Por su parte, el Magistrado MANUEL JOSÉ CEPEDA, en salvamento de voto que le hiciera a la sentencia antes referida, sostuvo:

"Por otra parte, la asimetría en el manejo de la información implica no sólo una desigualdad en el poder de negociación sino, de hecho, una enorme desventaja para el cabal ejercicio del derecho a la defensa de los 
consumidores. Si un comprador sufría un daño debido a un defecto del que adolecía un producto adquirido en el mercado, y quería dirigirse no contra el vendedor sino contra el productor con el cual no celebró contrato alguno, según las reglas clásicas de responsabilidad civil extracontractual, debía demostrar: (1) que sufrió un daño (2) que el daño fue causado por un defecto en el producto fabricado por el productor demandado y (3) que fue culpa de éste, bien porque actuó dolosamente o porque actuó negligentemente. Inmediatamente surgen los siguientes interrogantes: ¿Cómo puede un consumidor promedio conocer los estándares de producción de una fábrica? ¿Cómo determina si ese estándar es adecuado o no? ¿De qué manera puede controvertir en un plano de igualdad los argumentos que presente el fabricante, asesorado por técnicos y expertos en la materia, para desvirtuar las relaciones de causalidad? Contrario a lo sostenido por el demandante en el presente proceso, no es el productor quien ve restringido su derecho a la defensa, son los consumidores quienes, en virtud de las cargas en materia probatoria y de su precario acceso a la información relevante para solucionar el caso, ven menguadas sus posibilidades reales de defensa.

"(...)

"3.2. El segundo gran obstáculo para la cabal defensa de los derechos de los consumidores era el régimen de responsabilidad. Como se mencionó anteriormente, permitir que un fabricante responda por los daños ocasionados por sus productos defectuosos, según el régimen clásico de responsabilidad subjetivo, lo ponía en situación de ventaja frente a los consumidores. En efecto, en el caso de que el afectado pudiese llegar a demostrar adecuadamente que sufrió un daño provocado por un producto, que éste tenía un defecto y que ese defecto fue la causa del daño sufrido, además tenía que probar que el fabricante no había actuado con la diligencia debida en la elaboración de la cosa, es decir, que el defecto se debió a su negligencia.

"Esta situación ha sido corregida sustituyendo "la culpa del productor" como fundamento de la responsabilidad, por las "órbitas de control" del productor. Es decir, que el productor deje de responder por los daños que causa por su culpa (por negligencia o dolo) y responda por los daños cuyas causas se encontraron bajó su órbita de control. Para lograrlo, se han seguido diferentes vías. Jurisprudencialmente, por ejemplo, se presume la culpa del fabricante si el afectado demuestra que la causa se encuentra dentro de las órbitas de control, invirtiendo así la carga de la prueba a favor del consumidor (Alemania).

"Normativamente, se ha fijado expresamente un régimen de responsabilidad objetiva. Tal es el caso, por ejemplo, de la Directiva del Consejo de las Comunidades Europeas del 25 de julio de 1985 (85/374/CEE), una de las fuentes de inspiración del artículo 78 de la Constitución Política de 1991 en donde se adoptó este régimen de responsabilidad por que se consideró: '(...) que únicamente el criterio de responsabilidad objetiva del productor permite resolver el problema, tan propio de una época de creciente tecnicismo como la nuestra, del justo reparto de los riesgos inherentes a la producción técnica moderna.'

"(...)

"La norma consagra cuatro causales: fuerza mayor, el caso fortuito no sobrevenido por su culpa, el uso indebido del bien o servicio por parte del afectado y el hecho de un tercero. Al decir que el fabricante solamente se puede exonerar por esas razones está excluyendo "el haber actuado diligentemente". La responsabilidad no se funda en haber ocasionado un daño a otro por su actuación dolosa o negligente en la elaboración de un producto. Incluso podría demostrar el fabricante que actuó con diligencia, y, en todo caso, no se eximiría de su responsabilidad.

"(...)

"De esta forma, la responsabilidad del fabricante por los productos elaborados dejó de ser un problema jurídico regido exclusivamente por el principio según el cual toda persona debe responder por el daño que cause a otro por su propia culpa ${ }_{i}$ la regla según la cual los consumidores deben garantizar la apariencia y la confianza en las relaciones de consumo, se ha considerado una solución más justa y encuentra sustento en la protección efectiva de los derechos a la vida, a la salud y a la seguridad de los consumidores. En otras palabras, el fabricante más allá de garantizar que al elaborar su producto actuó de buena fe y con diligencia, debe garantizar que ese producto no va a causar daños. Por eso, las excusas posibles (fuerza mayor o caso fortuito, por ejemplo) deben romper el vínculo de causalidad. Es decir, el fabricante no puede pretender eximirse de responder por el daño demostrando que cumplió con los requisitos exigidos por la ley y actuó con diligencia y sin dolo. Debe 
Ahora veamos a qué tiene derecho el consumidor, como parte de la garantía. Primero que todo, a la entrega material oportuna del bien y su correspondiente registro si se requiere $^{18}$. Siempre hubo una discusión eterna en torno a que si como garantía se podía o no reclamar la entrega del bien cuando el vendedor incumplía con su obligación, hoy esta discusión queda a favor del consumidor.

Además, el consumidor tiene derecho a recibir gratuitamente los manuales de instalación, uso o mantenimiento, de acuerdo con la naturaleza de estos y en idioma castellano $^{19}$. Es muy importante entender que la obligación es de "suministrar" los manuales y no, como se ha vuelto costumbre, de remitir al consumidor a complejas páginas web para que busquen los manuales por su cuenta. En estos casos, se entiende que no fue entregado el manual, y por tanto en caso de que el bien sufra daños por la instalación, uso o mantenimiento no acordes con los señalados en los instructivos no le será imputable la responsabilidad al consumidor. Y si el consumidor, a pesar de haber recibido los manuales, desea contar con personal técnico especializado para la instalación y mantenimiento del producto adquirido, es obligación tanto del productor como del expendedor disponer de ellos para que le presten el servicio al consumidor, servicio que puede ser cobrado por aparte 20 .

Una vez el producto ha presentado fallas dentro del término de la garantía, el nuevo Estatuto establece, como primera obligación, la de reparar el bien y dejarlo en perfectas condiciones. Esta es una obligación para el productor o el proveedor, pero también es un derecho. Es muy usual en los consumidores que con la primera falla ya exijan el reemplazo total del producto por uno nuevo o la devolución de su dinero; la Ley, tratando de guardar el equilibrio entre el derecho de los consumidores y la estabilidad de los empresarios, determinó que si es posible arreglar el bien y dejarlo en perfectas condiciones, se podrá hacer. Si no es posible, el mismo numeral advierte que se deberá cambiar por uno de iguales o mejores características, o devolver el dinero pagado.

En caso de repetirse la falla, el consumidor podrá determinar la forma en que le deben cumplir con la garantía, dependiendo de las características del bien y del tipo de falla, y podrá consistir en: una nueva reparación, la devolución total o parcial del precio pagado o el cambio total o parcial del bien. En este último evento, por uno de similares o mejores características que el adquirido.

Un concepto nuevo que se incluye dentro de las obligaciones de la garantía es el de mantener repuestos, partes, insumos y mano de obra calificada para que el bien funcione adecuadamente, incluso después de que ha vencido el término de la garantía inicial, por un periodo de tiempo determinado por la autoridad competente $\mathrm{y}$, a falta de regulación, por la que indique el productor. En el caso de que este no lo anuncie, será por el tiempo

demostrar que la causa del daño no fue el defecto en el bien, pues el fabricante es responsable de los daños causados por los productos por él fabricados". 
de vida útil habitual para productos similares. Por regla general, se ha considerado que los edificios y los bienes inmuebles tienen un término de vida útil de 20 años, los vehículos de 10 años y los electrodomésticos "principales" como los televisores, lavadoras, secadoras, estufas, etc., 5 años. Claro que es una simple referencia, puesto que se espera que un inmueble dure mucho más de 20 años; algunos vehículos duran más de 10 años y otros menos, y así con todos los demás bienes. Por eso es tan importante que sea el mismo productor el que determine por cuánto tiempo garantizará la existencia de repuestos y mano de obra que permita a los consumidores disfrutar del bien.

Mención particular de garantía tienen los servicios especiales, tales como los que se consideran de medio, los que suponen la entrega de un bien o los de elaboración de un producto a la medida. Veamos cada uno de ellos. El artículo 7 establece que "[e]n la prestación de servicios en el que el prestador tiene una obligación de medio, la garantía está dada, no por el resultado, sino por las condiciones de calidad en la prestación del servicio, según las condiciones establecidas en normas de carácter obligatorio, en las ofrecidas o en las ordinarias y habituales del mercado". Esto quiere decir que, si bien el abogado o el médico no puede garantizar ganar el proceso o salvar al paciente, el consumidor sí puede esperar de ellos su mayor diligencia y cuidado como profesionales que son. El abogado deberá ejercer todas sus actuaciones dentro de los términos establecidos en la ley, y el médico deberá atender al paciente en el momento en que este lo requiera. En caso de incumplimiento, además de tener que devolver todas las sumas pagadas por el servicio, eventualmente tendrían que indemnizar los perjuicios que cause su actuar negligente.

En los servicios que suponen la entrega de un bien, como la reparación de un vehículo o un electrodoméstico, o el servicio de lavandería, quien presta el servicio deberá expedir un recibo en el que conste la fecha de recepción y el nombre del propietario del bien o de quien hace su entrega, así como su dirección y teléfono; la identificación del bien, la clase de servicio que presta, las sumas que se abonan como parte del precio, el término de la garantía que se otorga, el valor total del servicio -en caso de que sea posible determinarlo desde un primer momento- y la fecha de devolución. En caso de que no sea posible determinar estos dos últimos elementos en el momento de su recepción, el prestador del servicio deberá informárselo posteriormente al consumidor y dejar constancia de su aceptación expresa. En los casos de servicio de parqueadero, también se deberá expedir un recibo con fecha y hora de recepción del automotor, su identificación, el estado en que se encuentre y el valor del servicio en la modalidad en que se preste. En todos los casos, de no dejarse anotaciones expresas del estado en que se encuentra el bien, se presume que fue entregado en buen estado y con todos los elementos que lo componen, a excepción del motivo por el cual fue solicitado el servicio. Por tanto, quien presta el servicio asume la custodia y conservación del bien, así como de todos sus equipos anexos o complementarios si los tuviere ${ }^{21}$. En caso de pérdida o deterioro 
del bien en la prestación del servicio, la garantía consistirá en repararlo, sustituirlo por otro de las mismas características o pagar su equivalente en dinero ${ }^{22}$.

Volviendo a la forma como se debe cumplir con la garantía, una vez el producto esté listo para ser devuelto al consumidor, el que atendió la garantía deberá expedir una constancia de reparación indicando el tipo de reparación efectuada, las piezas reemplazadas o reparadas, la fecha en que el consumidor hizo la entrega del producto y la fecha de devolución del mismo, con el fin de dar trazabilidad a las reparaciones hechas y al tiempo en que el consumidor ha estado privado del uso y disfrute del mismo.

Por último, los productores, proveedores y terceros especializados podrán otorgar garantías suplementarias a la legal cuando amplíen o mejoren la cobertura de esta, de forma gratuita u onerosa. En este último caso, deberán obtener la aceptación expresa por parte del consumidor. Cuando un bien se adquiera en el exterior con garantía global o válida en Colombia, el consumidor podrá exigirla al representante de marca en nuestro país y solicitar su efectividad ante las autoridades nacionales, pero deberá demostrar que lo adquirió en el extranjero.

Como conclusión de todo lo anteriormente dicho, quisiera resaltar la especialidad de la responsabilidad en el derecho del consumo, que es totalmente diferente a las clásicas responsabilidades contractuales o extracontractuales que estudiamos en la universidad. En la responsabilidad por garantía, podemos deducir los siguientes elementos:

a) La garantía es una obligación de origen legal, o de igual manera puede ser contractual mientras ésta mejore y amplíe las condiciones de la primera. No pueden comercializarse en Colombia productos nuevos que no tengan garantía.

b) El legitimado para reclamar por garantía es el consumidor final, es decir, quien utiliza el bien para destruirlo en su consumo, y lo utiliza con una finalidad propia, privada, familiar, doméstica o empresarial cuando no está ligada con su actividad económica.

c) El consumidor podrá reclamar solidariamente al productor, que se presume fue quien puso su marca o enseña comercialen el producto, o al expendedor, probando que fue este quien lo puso en circulación. No requiere ningún tipo de vínculo contractual con alguno de los dos para poder reclamar.

d) El consumidor solo estará obligado a probar el defecto del producto dentro del término de la garantía, y será el productor y/o expendedor el que asuma la carga de la prueba de demostrar que el defecto surgió por alguna de las causales de exoneración de responsabilidad establecidas en la ley.

e) Las causales de exoneración de responsabilidad son taxativas y todas se pueden concretar en una sola: el defecto del bien surgió por un hecho totalmente extraño, ajeno a la órbita de control del productor o proveedor, lo que lo convierte en una responsabilidad objetiva.

f) La obligación será de hacer (reparar) o dar (cambiar el producto por otro o devolver el dinero). 
BIBLIOGRAFÍA

Ley 1480 de 2011 - Estatuto del Consumidor.

Decreto 3466 de 1982 - Estatuto de Protección al Consumidor.

Sentencia C-1141 de 2000 M.P.: Eduardo Cifuentes Muñoz.

Sentencia C-973 de 2002 M.P.: Álvaro Tafur Galvis. 